\title{
MONEY ILLUSION: RECONSIDERED IN THE LIGHT OF COGNITIVE SCIENCE
}

\author{
János VINCZE \\ (Received: 15 April 2018; revision received: 9 July 2018; \\ accepted: 8 September 2018)
}

\begin{abstract}
A basic principle of economics is that people always prefer a larger set of opportunities. Money illusion can be considered as the phenomenon when people may not correctly perceive their budget constraints, and may act in ways that run counter to this preference. In this interpretation, money illusion is a cognitive bias, worthwhile to overcome. Herein I argue that taking a view of human decision-making based on certain strands of cognitive psychology, one can reinterpret the evidence for money illusion in two ways. First, I claim that money illusion is inescapable to some extent, and saying that we suffer from it is similar to alleging that we experience optical illusions, only because we are unable to see, say, individual atoms. Second, taking a view on "preferences" different from the traditional one, I contend that it may bring little benefit to get rid of money illusion even in the cases where it is possible to do so. To follow up the visual analogy, even if we can improve our eyesight it is not obviously desirable. These arguments seem to lead to a Candidean disposition: there is no possible improvement on the state of affairs as far as "money illusion" is concerned. Nonetheless, I will make some positive proposals concerning economic policy and economics research.
\end{abstract}

Keywords: money illusion, ecological rationality, knowledge representation

JEL classification indices: B10, D91, E40

János Vincze, Professor at the Corvinus University of Budapest and Research Fellow at the Center for Economic and Regional Studies of the Hungarian Academy of Sciences, Institute of Economics. E-mail: janos.vincze@uni-corvinus.hu 


\section{INTRODUCTION}

\subsection{The money illusion problem}

Economic textbooks assert that money is, first of all, a means of exchange (see, for instance Mankiw 2009, Ch. 21). Clower (1967) defined it more formally: money is a commodity that is exchangeable for (almost) any other commodities. Then the textbooks proceed by telling us that money has other functions, such as store of value and unit of account. General exchangeability is the distinguishing property of money since many other (durable) goods serve as store of value, and the unit of account function is shared with non-moneys and "non-commodities", as "pure" units of account have always existed (Weber 1996)). Most economic models make the additional assumption that money is a good that does not enter directly into the utility functions of agents, or, in other words, it has only indirect utility.

In most expositions the unit of account function is played down, it is mentioned only for the sake of curiosity, and then gets hardly any attention. On the one hand, in standard microeconomics it is emphasized that, in principle, any good can serve as the unit of account. On the other hand, modern Neoclassical "New-Keynesian" theories attribute a special role to money prices, by pointing out that instantaneous market clearing is not attained because of the rigidity of prices set in nominal (i.e. money) terms. But the reason why prices are set in nominal terms is not derived from first principles, it is usually accepted as an empirical fact. In fact, money as a unit of account involves in it a deeply disturbing problem: that of money illusion.

A long tradition in economics can be epitomized by the sentence: "Money is a veil" (Pigou 1949). Money illusion can be formulated as the phenomenon that some people sometimes behave in ways as if they did not realize that it is true. While economic information is presented to us in monetary terms (money prices, money income and wealth in monetary units), some of us cannot see through the veil, and consequently, they make decisions against their own best interests: they disregard the changes in the price level, thus they confuse nominal and real prices.

Economists are proud of being able to reach out beyond appearances, and this short phrase is probably one of the main triumphs of economics. I think very few uninitiated persons understand its deep meaning, though experience shows that it can be taught, and those who apprehend it, might acquire a sense of its veracity as something inevitable. A few semesters in micro- and macroeconomics would probably be enough to make a second nature of the idea that money has only "indirect" utility, i.e. people acquire money in order to spend it on real things (goods or services). In other words, what really matters for them is the purchasing power 
of money (the quantity of goods and services one can buy for a certain amount of it), and not its mere nominal value.

Please notice that I'm not sarcastic: despite the fact that I'm going to offer a view that is different from this, I must acknowledge that the traditional conceptual framework of economics with preferences or utilities defined on the states of nature is a great intellectual achievement, certainly superior to naïve or folk economic ideas that have no notions of real money, price-indices, direct and indirect utilities and so on. Even the assumption of monotonic preferences ("more is always better”), admittedly an auxiliary assumption, can be accepted as a very good first approximation to explaining economic behaviour in many contexts.

But admitting the usefulness of the traditional framework does not mean that we should not recognize its limits, and whenever these limits are reached, one needs to seek new avenues. When modern economics was born, the contemporary psychology could not give much ammunition to a clear and analytical approach to economic decisions. In the last decades, however, cognitive psychology has progressed even in ways of formal modelling, giving us hopes that its otherwise well-known achievements can be readily adopted by economists who have developed a predilection for mathematical models as a necessary precondition for a theory.

\subsection{Money illusion in the economic literature}

It is believed that Irving Fisher was the first who coined the term "money illusion" (Fisher 1928). Later on, money illusion came to be strongly associated with Keynes's General Theory. He used it as a temporary assumption to explain unemployment through the hypothesis of downward wage rigidity. However, the intellectual trends of the mid- $20^{\text {th }}$ century favoured the idea that the rest of the humankind is not fundamentally different from the economists, and the fortune of money illusion was, as it were, reversed: money is a veil, and money illusion is, at worst, temporary and negligible. Probably it is telling what James Tobin (a Nobelprize winner generally regarded as a Keynesian) wrote in his 1972 address to the American Economic Association: "an economic theorist can of course commit no greater crime than to assume money illusion” (Tobin 1972).

However, dissident voices always existed (e.g. Modigliani - Cohn 1979; Akerlof et al. 1996; Shiller 1997; Bewley 1998), and as psychology and economics joined forces a slow but significant change in the attitude towards money illusion emerged among economists. By now even experimental and neuroscientific evidences have been marshalled to make the idea of money illusion acceptable, 
and it has become a building block of the psychological reinterpretation of macroeconomics in Akerlof - Shiller (2009, Chapter 4).

Behavioural economics is widely identified as an application of modern psychology in economics, where psychological discoveries find their way into mathematical models comparable to those that had been used in economics for at least a hundred years (Camerer - Lowenstein 2004). However, I share the opinion of those who believe that economists have abducted psychology in this marriage, and shaped it according to their own tastes (Berg - Gigerenzer 2010). While admitting that behavioural economics is a great improvement on traditional economics, I also believe that it has, in some ways, warped it, and is impeding progress eventually. Instead of generalizing the traditional conceptual framework, more fundamental changes, i.e. a radically new framework, would have been needed. ${ }^{1}$ This new framework (as a set of ideas) is available in the form of existing cognitive architectures, a subfield of computational psychology. In this paper, I make use of the notions incorporated in this field, and derive their implications for the treatment of the money illusion problem. The key concepts turn out to be explicit and implicit knowledge representation, and my principal claim is that an "illusion-free" explicit representation of value is infeasible, therefore we are bound to suffer from money illusion, though are not helpless about it.

$$
* * *
$$

Section 2 describes the cognitive framework in which I analyse money illusion. Section 3 presents the basic money illusion evidence, and its reinterpretation. Section 4 enlists our ways of handling money illusion, and Section 5 takes hints about the psychological origins of money illusion. Finally, in Section 6, after summarising the argument, it is shown that positive conclusions can be obtained, too.

\section{A COGNITIVE APPROACH TO ECONOMIC DECISIONS}

One of the most widely accepted tenets of cognitive psychology is that the mind builds and acts on internal representations of the outside world, and we have at our disposal several representations for the same problem. Shafir et al. (1997) suggested that money illusion is a case of improperly using a certain kind of representation (a "nominal" one), whereas the correct thing would be to apply

1 Concerning the relationship between psychology and economics, the general argument in this article follows that in Gigerenzer et al. (2008) and Berg - Gigerenzer (2010). My contribution is the emphasis on the role of knowledge representation, and the distinctions between different kinds of knowledge representations. 
a "real" representation. The authors assert that this is the salience and ease of nominal representations that make them alluring for us. This explanation leaves a number of questions unanswered. For instance, what do salience and ease mean in this context? How are the representations created, and what is their role in the decision process? How can we devise "real" as opposed to "nominal" representations? Why can it be that people act upon representations which lead them to decisions that seem to be at variance with their best interests?

Knowledge representation is missing from the economics literature, therefore I had to turn to psychology to look for theoretical frameworks that can accommodate the idea of a choice between representations, where "choice" may not entail consciousness. Cognitive architectures are computerized expressions of theoretical models of behaviour where knowledge representations play fundamental roles in the simulated activity of the mind (Anderson 2007). They are essentially computational theories of cognition, and have been used extensively by psychologists, neuroscientists and artificial intelligence (AI) researchers. Building cognitive architectures is a research programme that has its origins in the work of Herbert Simon (incidentally a Nobel-prize winner in economics), and Alan Newell. My discussion below draws on two sources: the Adaptive Control of Thought-Rational (ACT-R) cognitive architecture (Anderson 2007) and the Connectionist Learning with Adaptive Rule Induction On-line (CLARION) project (Sun 2003).

\subsection{Production rules and representation in the ACT-R cognitive architecture}

The ACT-R cognitive architecture has three important features: the distinction between declarative and procedural memory, a modular structure wherein different modules communicate with each other, and it implements rational analysis, a type of reinforcement learning.

Problem solving starts with an initial representation of the problem which depends ineluctably on the perceptual input. Then the program carries out information processing via the activity of the procedural module that may re-represent the problem and/or the goals. The procedural module works through production rules (i.e. "if ... then ..." structures). It looks for information in declarative memory where "factual" knowledge (propositions about the world) is stored. If a production rule's "if" part has a pattern that matches either a problem, or a goal or a fact, then it has the potential to "fire", that is, to carry out some computation defined by the "then" part of the rule. This computation can result either in the derivation of new facts, or in calling new procedures to work, or in giving a message to an output interface. 
There may exist cases where there are several matches, so there is a need for a mechanism that resolves possible conflicts. In ACT-R this is done by selecting one of the matched procedures by a probabilistic rule that takes into account their "utilities" (rational analysis). The "utility" of each procedure is updated at any time the simulated brain perceives a "reward". Mathematical formulas (based on the accepted theories in psychology) determine how rewards are converted into changes in the utility scores of procedures. Non-use is penalized, thus a procedure rarely employed has less and less chance to be applied, except if other competing procedures score even worse. ${ }^{2}$

\subsection{Explicit and implicit representation in CLARION}

CLARION features a dual knowledge representation approach: it distinguishes between explicit and implicit knowledge (or top and bottom level knowledge, respectively) (Sun 2003). Compared to ACT-R the novelty is the bottom (implicit) level. In this approach knowledge is not represented symbolically, like individually distinct concepts, sentences or rules, but in a distributed manner (sometimes referred to as a sub-symbolic representation). The representation of implicit knowledge is through neural networks, and learning in the bottom level takes the form of training of these networks. The declarative memory (called the "nonaction centred subsystem") at the bottom level consists of associative memory networks. Whereas at the top level knowledge can be likened to clear definitions and/or statements (similar to the declarative module in ACT-R), at the bottomlevel it is like "vague" associations between properties, interpreted as "intuitive", or non-conscious. The two subsystems are interrelated, and are combined when making decisions. There are possibilities to transport knowledge acquired on the "intuitive" level to the conscious (explicit) system, and vice versa.

CLARION also contains subsystems that control the whole cognitive process, called meta-cognitive and motivational subsystems. The idea is that we have primary drives (for instance "get food!") that control our behaviour through creating secondary drives (for instance, "get chocolate!”). Whereas primary drives are hard wired, secondary drives and goals are learnt and also possess explicit and implicit representations.

2 The concept of rationality in ACT-R seems to me very similar to the notion of ecological rationality (see among others Goldstein - Gigerenzer 2002; Berg - Gigerenzer 2010). Indeed, ACT-R appears as a computational version of the adaptive toolbox theory (Gigerenzer - Selten 2001; Gigerenzer - Gaissmaier 2011), which is also based on ecological rationality. 
For my purposes the dual nature of representations is a crucial addition made by this framework. According to this theory the decision-making process can be carried out on both the explicit and the implicit levels, and the two levels can interact in complex ways. ${ }^{3}$

Notice that in the case of the simple decision problem analysed above, there does not seem to be a need to use implicit knowledge. In this case, and in similar artificial (experimental) situations, the task is formulated in terms of, presumably, clear concepts, and it is not obvious how the "intuitive" subsystem can interfere in the decision. Still, the outcome of this experiment and that of similar experiments may be interpreted by invoking the non-conscious.

\subsection{Feasible representations of wealth (income)}

Money illusion is a problem with having and using representations of wealth. ${ }^{4}$ Let us look at an economic decision problem that most of us have met some time during our life. Suppose I receive an offer from a bank to place at least 1000 euros in a special deposit for one year with a promise to get it back augmented with a $5 \%$ rate of interest. To accept or refuse such an offer requires very complex reasoning. I give here only a few of the salient considerations that can cross one's mind.

- First, I have to look for alternatives. If I accept the offer, would I change my portfolio (the mixture of my assets), or shall I plan to change my spending strategy for the future?

- Second, what is the "value" of 1050 euros tomorrow (capital plus interest) compared to the "value" of the 1000 euros today?

- Third, I had a similar offer 3 years ago, which I accepted, was I satisfied with that decision, and if not, why?

3 The dual systems' view appears under different names in the psychology literature (Sun 2015). Compared to the alternatives, the theory incorporated in CLARION has a very important feature: the distinction is based on representations (symbolic or distributed). When we talk or write we use a symbolic, explicit representation, and therefore, it is not easy to describe sub-symbolic (distributed) representations in natural language. Perhaps the most we can say of them is that this type of knowledge cannot be told in so many words. A comparison between a least squares regression model and an artificial neural network may help to understand the distinction. Individual parameters are easy to interpret in the regression model, whereas individual nodes have no distinct meaning in the network.

4 Conceptually, income is the change in wealth per period of time. Therefore, I will refer to the representation of income and wealth interchangeably. 
To answer these questions I must have representations of the offer in mind. There exists obviously a nominal representation.

\section{Explicit nominal representations}

"I give now 1000 euros and get back 1050 euros in a year time.” This representation is defined in terms of a monetary unit which is used as a means of exchange. It is clear that nominal representations are not unique, as a conversion of euros to dollars or to other currencies is always feasible. The point is that these things are not what we are supposed to consume.

\section{Explicit real representation}

"I give now 1000 2017-euros, and will get back 1040 2017-euros based on the Eurozone's expected consumer price index (CPI).” There is no unique way to represent the offer explicitly in real terms. One can change the base year (2017), the CPI, or the method of calculating expected inflation (not even specified above). The essential point is to define purchasing power as equivalent to a certain amount of nominal money in terms of some real measurement unit. However, this representation involves several options, in fact more than a nominal representation.

\section{Implicit real representation}

In this case one cannot describe the representation succinctly. This is a major trouble with sub-symbolic representations: they defy symbolic representations. The offer of 1050 euros tomorrow for 1000 euros today becomes an input signal to a neural network together with other signals that may contain price information of many goods, and/or the CPI read in the newspaper. The network associates these signals with outputs, whose values can be implicitly interpreted as "the real value of euro", but it cannot be expressed in so many words. This output signal is not immediately and automatically accessible at the top level, but by the explicit knowledge subsystem, only in the context of some task, it is activated. For instance, if someone asks the explicit question: "can I buy for 1050 euros tomorrow the same amount of goods as for 1000 euros today?”, the implicit knowledge base can be queried to give an (intuitive) answer of "yes" or "no". And, the implicit real representation needs not be unique either. Different experiences can shape our intuitive knowledge base through our lifetime, though it may be conjectured that similar people would have functionally similar representations.

In the next section, I discuss the money illusion evidence in terms of these three representations. 


\section{THE MONEY ILLUSION EVIDENCE AND ITS REINTERPRETATION}

\subsection{The empirical evidence}

The lady with 50000 dollars

A lady inherited 50000 dollars in 1892, and this sum was given to a trustee who invested it in bonds. Irving Fisher (1927) accompanied her to the trustee in 1920, and listened to his boasting of keeping her wealth intact, as she still owned almost 50000 dollars in bonds. Fisher was quick to point out that this sum was worth much less than in 1892, and that the annual 2500 - 3000 dollars that the lady had received as income was simply eating up the principal. Fisher did not question the good faith of the trustee, and interpreted his failure to preserve the lady's fortune as an example of money illusion. Neither the lady nor the trustee had considered the "real" value of dollars, and thus, were satisfied with the outcome. Fisher explained him that during those 28 years of falling dollar the creditors-bondholders lost, whereas the debtors-stockholders won. According to Fisher, the trustee could eventually understand his reasoning, claiming only that it was not his fault.

How can we characterise her behaviour on the basis of the decision-theory outlined in the previous Section?

\begin{tabular}{l|l}
\hline & The widow's problem as seen by the lady \\
\hline Problem & Shall I keep the trustee? \\
\hline Goal & Determine whether he is a person who could preserve my wealth! \\
\hline Declarative fact & Wealth is measured in dollars. \\
\hline Heuristic 2 & If an advisor preserves the value of my wealth, then he must be kept. \\
\hline
\end{tabular}

As the dollar value of her portfolio did not decrease the lady kept the trustee for 28 years. Fisher thought that it was a big mistake, since just preserving the dollar value of the portfolio was not enough to preserve its real value (measured in purchasing power equivalent), and the trustee must have been fired. Fisher's solution can be characterised with the retrieval of an additional fact from declarative memory: The value of the portfolio must be measured in constant purchasing power dollars.

\begin{tabular}{l|l}
\hline & The widow's problem as seen by Fisher \\
\hline Problem & Shall I keep the trustee? \\
\hline Goal & Determine whether he is a person who could preserve my wealth! \\
\hline Declarative fact & $\begin{array}{l}\text { The value of the portfolio must be measured in constant purchasing power } \\
\text { dollars. }\end{array}$ \\
\hline
\end{tabular}




\begin{tabular}{l|l}
\hline & The widow’s problem as seen by Fisher \\
\hline Heuristic 1 & $\begin{array}{l}\text { If my portfolio’s value in constant dollars decreased, then the advisor did } \\
\text { not preserve my wealth. }\end{array}$ \\
\hline Heuristic 2 & If an advisor did not preserve wealth, then he must be fired. \\
\hline
\end{tabular}

Thus the new representation would lead to a different decision. At some point between 1892 and 1920 the lady would have realised that her portfolio lost part of its purchasing power, and she would have fired the trustee. The difference in behaviour would have been due to the re-representation of the goal in real terms. However, one can ask whether the average man could master the concept of constant purchasing power dollars. This tale and several other stories of Fisher seem to indicate that even professionals (businessmen, financial advisors) do not use explicit real representations. Having an explicit real representation has some prerequisites: 1 . To know and understand the usefulness of the concept of deflating by a price index; and 2. Being aware of and repeatedly retrieving the numerical value of the index. Today a large number of people acquire a basic knowledge of economics, and thereby, of price indices and inflation adjustment. Nevertheless, as the analysis of the other examples will show, explicit real representations are rare, and even then, "fleeting".

What about an implicit real representation? It is perhaps more surprising that the story indicates that not even implicit knowledge of the change in the real value of the dollar was present in the minds of the protagonists.

As the cognitive model described above suggests heuristics and (involved) representations must be learned, and are in competition with each other. Then, one must ask what advantages the lady would have had by owning either an explicit or an implicit real representation of value. For the time being let us take it for granted that getting rid of the underperforming trustee is a "good" decision. Can we formulate another behaviour resulting in exactly the same outcome?

\begin{tabular}{l|l}
\hline & The widow's problem from a different perspective \\
\hline Problem & Shall I keep the trustee? \\
\hline Goal & $\begin{array}{l}\text { Determine whether the trustee is a person who preserves my wealth better } \\
\text { than other trustees preserve the wealth of their clients. }\end{array}$ \\
\hline Declarative fact & Value is measured in dollars. \\
\hline Heuristic & $\begin{array}{l}\text { If the goal is to "Determine whether the trustee is a person who preserves } \\
\text { my wealth better than other trustees preserve the wealth of their clients", } \\
\text { then ask your friends about the change in values of their portfolios, then } \\
\text { compare their returns with your own return, and, if it is not lower, retain, } \\
\text { but if it is lower, fire the trustee. }\end{array}$ \\
\hline
\end{tabular}


The heuristic here looks like a complex one, but, in fact, it is an instantiation of a general social heuristic which suggests that you should seek advice from your social circle (Pachur et al. 2004), and the principle that abilities must be judged by relative performance. It is likely that this latter - more complicated - behaviour must have resulted in the firing of the trustee at some time. Let us compare the two "successful" procedures!

The relative performance procedure has certain advantages over the procedure based on real representations. First, real representations (either explicit or implicit) can be easily "forgotten" if they are not used frequently, whereas the second procedure is built on the instantiation of a general purpose heuristics. Second, it is based, in general, on a better measure of advisory performance, since it may occur that investment outcomes are so poor that even the best advice is not sufficient to get positive "real" returns.

Apparently the lady was not dissatisfied with the performance of her portfolio. There is no need to judge her behaviour as rational or irrational. The only point I would like to stress here is that if her behaviour had required correction, there would have occurred an easier way to rectify it, than to learn how to represent real value.

\section{A German shopkeeper during hyperinflation}

The scene is the outskirts of Berlin, the date is 1922. Fisher is buying a shirt and is talking to the shopkeeper, whom he finds very intelligent. Fisher thinks that the price is extremely low, and is surprised by the unwarranted generosity, but the woman answers that she is gaining a small profit because she has paid less for the shirt in the first place.

Fisher and Thaler (1997) comments on this story in an article where he gives the honorific title of "behavioural economist" to Fisher - finds here again an example of money illusion. The woman does not understand that she is making a loss rather than a profit in real terms, because she does not understand that the purchasing power of the Mark has significantly dropped, due to the $50 \%$ general price increase between buying and selling the shirt.

The shopkeeper's problem was "how to price the shirt?", and she apparently used the heuristic of pricing in terms of acquisition cost, measured in money. Judging by her comment on profitability, the shopkeeper did not use a real representation (either explicit or implicit). But what would she have gained with the access to a real representation? It would have meant that she would have priced the shirt Fisher bought in constant-Mark terms (the case of an explicit real representation) or, at least, would have made some upward "inflation" adjustment (a likely consequence of an implicit real representation). She may have made a 
business mistake when she calculated profits in money terms, but the mistake may have been there if she had made the calculation in "real" terms. To wit: from a "rational" profit-maximizing point of view shirts must be priced at current opportunity costs, and not at historical costs. Pricing based on historical real costs might make things worse in certain circumstances, though may be an advantage if the replacement price of shirts moved roughly together with general inflation. (Judging by the Chart on Fisher (1927: 9) he made this latter assumption tacitly.) Then pricing in "real" terms may be an improvement, with which one could replace the burden of monitoring competitors' and suppliers' prices, but it is not the first best solution.

Representations may have an effect on the evaluation of the situation. Thinking that she has made a profit might have given her a positive reinforcement, otherwise she would have felt frustrated because of losing money. Whether this "mistake" in experiencing utility is a mistake at all is a deep question that I could not consider here. I just want to notice that as long as she behaved irrationally it was not an immediate consequence of money illusion, but rather of the bounded rational habit of acquisition costs based pricing. The fact that the woman must have grown up in an environment where prices were stable might have contributed to this error, as acquisition and opportunity costs usually do not differ much if the general price level is stable, and, in such circumstances, acquisition costs based pricing could not be detected as mistaken.

The mistake is caused by the interplay of the nominal representation and acquisition cost based pricing. This duo works tolerably well under stable price levels. The switch to opportunity cost pricing is the first best solution, in principle, but it needs monitoring the opportunity costs, an activity which is not free. Having an explicit real representation of acquisition costs would have been an improvement, but not a perfect solution. Having an implicit real representation may have led to a search for an alternative procedure, perhaps to opportunity cost pricing. Thus, in this case again, real representations may have helped in bringing about the good solution, but it might have been obtained without them, just as well.

Another element in this story is her insistence on being honest, and not a profiteer. It appears as a separate motive that might have had a role in her pricing decision. Fisher relates other stories where this fairness motive shows up in strange and, apparently, self-destructive ways. Fisher (1927: 8) told an American woman's case, who had to repay a loan in Germany after the Great War. She thought that she owed 7000 US dollars, and was surprised when it turned out that she should pay only the equivalent of 250 dollars, due to the depreciation of the Mark. She even insisted on ethical grounds to pay 7000 . Thus, Fisher commented that if she had wanted to be fair in real terms, she must have offered 12000 
dollars, equivalent to "buying power" of 7000 pre-war dollars. Unfortunately, he does not specify whether this buying power calculation refers to the Mark's or the Dollar's buying power. I guess this is the Mark's, in which case one may ask why an American woman should be concerned with the Mark's purchasing power. For her fairness was "defined" in terms of American dollars, and for the Berlin shopkeeper, in the previous example, in German marks. Incidentally, we can see a serious problem here with explicit representations of real value. The relevant price indices for making the deflation operation are "personal" rather than interpersonal. It makes difficult to agree on what fairness means if the measures are not commensurable. Thus if we are concerned with fairness, nominal representations may dominate real representations.

\section{Long-term contracting in money terms}

Shiller (1997) made the obvious observation that all over the world most payments are contracted in nominal terms, and indexation (by whatever price index) is extremely rare, except under conditions of high inflation. He points out that the price level, in the long run, is very unstable, and its forecast beyond a few years is highly imprecise, thus nominal contracting poses substantial risks both to creditors and debtors. Indexation must confer benefits for risk management reasons, and why the public resists it is a major puzzle for economic theory. With reference to history he could cite the prominent economists, even from the nineteenth century, who advocated indexation, as yet to not avail. We have here an issue which is indeed puzzling. Something that is mutually beneficial, is known to many people, and still, could not take root. Shiller conducted an in-depth empirical investigation into the psychological-cognitive reasons why this is so. Using questionnaires in the US and Turkey, (where the puzzle was even more acute because of high and unstable inflation) he did not obtain a simple explanation, but uncovered a number of interesting facts.

First, it was shown that many, though not all, people can understand the advantages of indexation. Second, money illusion manifests itself very clearly when justifying nominal contracting, people say: "I want to know how much money I will be getting". And these are often the same ones who have just correctly explained how indexation preserves real buying power (Shiller 1997). Third, the future uncertainty of the price level is not appreciated in general. Fourth, many respondents believed that public price indices did not reflect their personal price indices.

Shiller's evidence exhibits that people acquire some concept of "real money", but this concept is more implicit than explicit, largely qualitative, and depends on specific circumstances. The inconvenience of real representations is reflected 
in the fact that those countries that have introduced indexation under very high inflation, drop it after inflation has abated.

It is clear that indexation must be agreed on by the parties to a contract. In practice, it is necessary that many people be in agreement with it, as it is very unlikely that for the sake of a few of us banks will tailor their contracting terms. It seems that this agreement is widespread only at high levels of inflation, and even then indexation takes the form of variable interest rates rather than linking capital repayment and interests to some price index. Indexation, after all, affects the division of some uncertain "pie" between creditors and borrowers, and we may guess that the nature of the value representation affects mutual understanding, on which bargaining must be based. If the price indices are individualized, "real” representations are incommensurable, and mutual understanding is jeopardized.

\section{Nominal valuation formulas}

In 1979, Modigliani - Cohn arrived at the striking conclusion that the market had been undervaluing equities for ten years due to money illusion. They identified two kinds of mispricing: 1 . using nominal discount rates, and 2. neglecting the real revaluation gains on debt during times of unexpectedly high inflation. The latter is a recurring topic, as not recognizing revaluation of gains (or losses) was a leitmotif of Fisher's analysis, too. But here the issue seems to be more serious and incredible. The authors confess that when the idea first occurred to them they swept it away as very unlikely. Is it believable that professionals producing these valuations are really unknowledgeable about inflation adjustment?

Besides providing indirect (statistical) evidence Modigliani and Cohn perused internal memoranda of large brokerage houses. They found direct evidence that valuation formulas indeed used nominal, rather than real, discount factors (though some adjustment for inflation existed), and largely ignored real revaluation. It seems then that money illusion (not adjusting adequately for price level changes) is not only a problem for the uneducated public.

At first sight it is indeed hardly believable that finance professionals are unaware of the difference between real and nominal rates and the effect of inflation on real asset values. The most obvious explanation is that they do not have a common explicit real representation of value and would be loath to communicate something ambiguous to their investors. For instance, what is the deflator index for a dentist in Luxembourg, and that for a Japanese businessman? Long term real discount factors must be estimated, and probably no widely (globally) accepted method is available. The multiplicity of possible explicit real representations makes them unsuitable for communication to a wider public. 


\section{Downward nominal wage rigidity}

The infrequency of nominal wage cuts is normally regarded as evidence for money illusion. Traditional reasoning tells us that firms and workers must care for the purchasing power of wages rather than their mere monetary value. A piece of strong evidence for nominal wage rigidity comes from studies showing that even in recessions money wages do not fall. See for instance Bewley (1998), where this is documented via questionnaires. This study indicates that money wage cuts are regarded as unfair and are feared to destroy morale within firms, with the attendant negative consequences on productivity and future hiring. Alternatively, when inflation is positive workers frequently consent to unchanged nominal wages. Interviewees reported that nominal, rather than real, wage cuts are considered unfair and incur retribution costs. Here one meets money illusion again; it seems decisions are conditioned on nominal wages, while presumably the true interests of workers and owners lie with "real" income.

Other things being equal, a nominal wage reduction decreases instantaneously the wage-earner's wealth (whichever representation he uses), while it also implies some redistribution of wealth between him and his employer, thus raising a fairness concern. However, the very concept of redistribution presupposes commensurability. Implicit real representations could not very well serve to compare the relative position of employees and employers. Then to have a common concept of unfairness, at least, the representation of wealth must be common, and this can be achieved only by an explicit representation. The non-existence of common explicit real representations makes any individual real representation useless as far as bargaining through "fairness" is concerned.

Should employers not be afraid of the retaliations in the form of lower productivity if only real, but not nominal, wages fall? If employees had only nominal representations of wealth, then they should not. However, if there are implicit real representations then the answer is "probably". Then employees would feel sooner or later that both of their goals (having larger wealth and being treated fairly) are unfulfilled, and they would take action to remedy the situation. This might take a number of forms. There is a silent revenge (diminished morale, lower productivity), or there are more vocal possibilities (asking for compensating rises, or switching to more formal automatic indexing). Indeed, employees must have some implicit real representations if indexation ever comes to their mind.

\section{Assessment of economic success}

The paper by Shafir et al. (1997) was an influential one on the road to the rehabilitation of money illusion. The authors reported a series of questionnaire evi- 
dence showing that respondents react in many cases exclusively to nominal rather than to real valuations. Unfortunately, several questions contained elements that mixed money illusion with other supposedly psychological factors (e.g. fairness and morale). The second problem in their article is perhaps the one where the money illusion issue appears in isolation. Respondents were asked to rank on the basis of how well three (fictitious) characters had done. Each one had inherited a house of the same dollar value, and then sold it after a year at different prices under different circumstances. Adam sold it after a year of $25 \%$ deflation at a price $23 \%$ lower than its initial value. Ben sold it in a zero-inflation environment at nominal and real loss of $1 \%$. Carl sold it at $123 \%$ of its initial value, after a year of serious (25\%) inflation. Thus the nominal gains were:

$$
\text { Adam }-23 \% \text { Ben }-1 \% \quad \text { Carl }+23 \%
$$

whereas the real gains (as all learned economists could calculate from the given inflation data):

$$
\text { Adam }+2 \% \quad \text { Ben }-1 \% \quad \text { Carl }-2 \% \text {. }
$$

The replies were far from unequivocal. $48 \%$ of the respondents voted for Carl being the most successful, followed by Adam with $37 \%$. Ben was listed as the worst-accomplishing person by $10 \%$ of the respondents.

Shafir et al. (1997) hypothesised that our behaviour is conditioned on a mixture of real and nominal representations of the decision problems. Also they suggested that for many purposes there is no material difference in using either of the representations. For instance, in a static context the profit maximising choice is independent of the numeraire. The authors claim that nominal representations have the advantages of ease, salience and simplicity, and it is the reason why many of us apply them in preference to the "rational" real representation.

In terms of the ACT-R theory, respondents represented wages nominally because people have "standing" nominal representations, and, in any case, the questions were formulated in nominal terms directly. So everyone in the experiment must have had an initial nominal representation. Those who answered that they prefer larger nominal gains simply used a procedure, like "Higher value is preferable"; for them value was defined in dollars, and they simply ignored the inflation figures. This is the group exhibiting money illusion. Now the question is how we can reckon the behaviour of those whose answer was expressing preference for the wage that had the higher value after deflating by inflation. They must have developed a temporary (for the sake of the questionnaire) explicit real representation, based on the inflation figures provided by the interviewers. Probably not everybody has the analytical capabilities, the necessary knowledge or the incentives to accomplish this task. Simple logical operations may elude 
us, and in this case it was indifferent whether one made mistakes or not. But, certainly many people acquire some training in economics where real representations are taught.

Also, it is possible that other people have implicit real representations that are not quantitative. Though they may input figures like "prices increased by $2 \%$ since last year", they may not transform this information into numeric values, rather only into a vague feeling that wages are worth not as much when inflation is higher. It is possible that the variability of responses is caused by the presence of this ambiguous group, who have an implicit real representation, but cannot deliver the fully rational quantitative analysis.

\subsection{The interpretation of money illusion experiments}

Since the year 2000, several experiments were conducted to prove experimentally the existence of money illusion. Though these experiments have uncovered some interesting psychological and neurological facts, they provide little new information on the money illusion problem, as they do not address the problem of whether or how we represent real value in practice.

\section{Oligopoly experiments}

Fehr and Tyran (2001) conducted various experiments to show that money illusion matters in strategic situations. In all of these experiments agents played oligopoly pricing games. In some experiments payoffs were denominated (represented) in "points", i.e. in artificial units. Participants knew how to convert points into Swiss francs, the currency in which they were paid. In other treatments payoffs were directly given in Swiss francs. In each experiments there were two stable equilibria: one of them is dominant in "nominal" (point) terms, while the other one is dominant in "real" (Swiss franc) terms. Fehr and Tyran's main findings were the following: 1 . In both treatments people reached eventually the equilibrium dominant in the "currency" in which the problem was formulated. 2. When human opponents were replaced by machines, whose behaviour was predetermined (effectively changing the task from strategic to merely optimising), participants converged on the decision optimal in Swiss franc ("real") terms.

They interpret this evidence as showing that the nominal illusion is an important factor in strategic situations. They believe that people stick to the nominal representation because they are unsure whether their human opponents could switch to the real representation (strategic uncertainty). Note that in these experiments Swiss francs were considered as "real", whereas points as "nominal". If 
money illusion were some irrational attraction for "local money", then the participants should have preferred the real (Swiss franc) dominant equilibrium in any case.

The Fehr-Tyran experiments show that people are capable of building several representations of the same problem. However, in their experiments representations in points and in Swiss francs were the contenders, and not nominal and real representations. For me the experiments' lessons include the following: 1. Local moneys do not enjoy an undefeatable advantage as representatives of value. 2. The initial representation is preferred if coordination is an issue, and people want to make sure that others think like themselves. It is a framing effect, because the initial representation reflects framing, in this case controlled by the experimenter. People apparently do not trust others to carry out the cognitive feat of moving from the initial nominal ("point") representation to the Swiss franc representation. 3. The experiments do not tell anything about real representations. Thus, on the whole the experiments provide valuable information on cognitive mechanisms, but they bear on the money illusion problem only indirectly.

What does the fMRI signal?

Weber et al. (2009) looked for signs of money illusion in the activity of the brain. The medial prefrontal cortex is an area that has been shown to exhibit increased activities in response to "rewards". In the experiments participants accomplished some task, and were rewarded with a certain prize denominated in dollars and with the possibility to buy items from a catalogue. In other words, the money prize was "earmarked" that could be used only for some definite purpose. In one condition both prizes and prices were 50\% higher than in the other. As there were no other differences in "real" terms the experiments were identical. The functional magnetic resonance imaging (fMRI) measurement of the blood oxygen level dependent (BOLD) activity showed higher responses at the time rewards were assigned in the "inflationary" (higher nominal income and higher prices) condition. The authors interpret this as supporting evidence to Shafir et al. (1997) that our brain responds to the nominal representations rather than to the real ones. In addition, they found that this effect is stronger at those people who exhibit higher degree of money illusion in a questionnaire designed on the lines of Shafir et al. (1997).

My interpretation is as follows: Prizes were denominated in dollars, thus the initial representation of rewards must have been nominal, in dollars. It is understandable that a 150 dollar prize incites a greater BOLD response than a 100 dollar prize, since it is a higher nominal reward, and the brain has a nominal representation. When the prices in the catalogue are perceived, a temporary explicit 
specific real representation (tailored to the specific problem) may be formed that gives the same "real" value for the two prizes. Those who have relatively higher "expectations" of the 150 dollar prize tend to be those who can form explicit real representations less easily. As the money is "earmarked", the experiment does not give information about the real representations, as I use the concept in this paper.

\section{SURROGATES OF REAL REPRESENTATIONS}

My interpretation differs from that of Shafir et al. (1997) in that they seem to think that there is one "true" real representation, and nominal representations interfere with the application of that. I think there is absolutely no reason to believe in any "true" real representation. Real representations (either explicit or implicit) are not truer than any nominal representation. Their availability affects behaviour and the "well-being" of people, but that is all.

My claim is that explicit real representations do not exist permanently and the main reasons are their inherent multiplicity and individuality. Alternatively, implicit real representations can very well exist but are hard to communicate, which makes them serviceable only for a limited range of tasks. This leaves many people with nominal representations that have, occasionally, untoward consequences. When we become aware of the damages nominal representations may cause, we search for solutions others than forming real representations.

People look for surrogates of real representations usually when inflation is quite high. This is a situation when we "feel" most strongly that nominal values are not "real", and economic calculations require some quantitative measure of wealth (on a ratio scale) that is "stable". Switching to a foreign (stable) currency is a frequently employed solution, but from the cognitive point of view it is a substitution of one nominal representation with another. We have also seen that when inflation is abated, people are more than willing to switch back to a nominal representation in terms of their own currency, which is used in everyday life, and therefore comes more easily to mind as suggested by the ACT-R theory.

In capital markets, nominal interest rates normally reflect inflationary expectations. The variable rate contracts are also a well-recognized partial solution for the money illusion problem. A resort to shortening maturities and frequent renegotiation of contracts are not very pleasant, but can be regarded as improvements in the long-term nominal contracting. If the commonly accepted real representations existed, these imperfect solutions would disappear.

These contractual solutions are admittedly partial. How would a more complete solution look like? Shiller (1998) is in favour of introducing indexed units 
of accounts, like the Chilean unidad de fomento. Indeed, widespread indexation, with some commonly accepted price index, can be conceived as the introduction of an indexed unit of account, without explicitly giving it a name and unit. An indexed unit of account cannot drive out standard (means of exchange) money as some prices must be quoted in the legal tender in order that the index and the exchange rate between the two "moneys" can be definable. This dual system can survive, as it has survived in Chile and in many countries in the Middle Ages, where for centuries the means of exchange and standard units of accounts were different (e.g. Weber 1996). Shiller (1998) suggests the introduction of several artificial units, serving different objectives. In fact, Chile has had a special accounting unit for tax purposes. However, this solution of "multiple real moneys" may also have its shortcomings, and these shortcomings are related to cognitive factors. Perhaps the existence of multiple competing values is hard to digest for our brain, and retaining several explicit value representations for a substantial time is not easy.

\section{THE SOCIO-PSYCHOLOGICAL BASIS FOR MONEY ILLUSION}

Lea and Webley (2006) argue that money illusion is incompatible with what the authors call the Tool Theory of Money, whereby money is a means for achieving certain goals (real consumption). The "Tool Theory" is another name for the classical economic approach with respect to the functions of money. The authors advance the Drug Theory of Money, according to which money is like a drug, i.e. something which is desirable in itself by producing certain physiological effects on the brain. Their hypothesis is that money parasitizes on basic human instincts, like the instinct to trade (related to reciprocal altruism), and object play. The idea of money as drug can explain why people seem to care for monetary values without bothering to figure out the purchasing power of money prizes.

There exists another area of research that can shed light on the psychological bases of money illusion. Economists have their usual foundational story about money: money's role is the facilitation of barter, but money is not the essential thing. However, ethnographers have long claimed that historically money has never come into being as a solution to the "double coincidence of wants" problem (See Graeber 2011 and Martin 2013 for a summary of the ethnographic evidences). Rather, the genesis of money is intimately related to debt (Graeber 2011, Ch 2.). Graeber (2011, Ch 3.) emphasises that the concept of being in debt is an important social psychological fact in many ancient and non-industrial societies. Ancient religions hold that there exists some primordial debt and debt is an essential feature of human existence. According to Graeber, money can be regarded 
as an invention that enabled men to quantify debt and to work out detailed rules about its management. Likewise, Martin (2013: 21) claims that the transferability of debt was a revolutionary idea, and money served for this purpose as a unit of account. Clearly, any quantification makes sense only if it is inter-subjective, thus money was created as a measure of abstract universal value. Thinking in terms of money thus became a fundamental thing in social consciousness. It seems that debt had much more significance as an organizing principle of human relations than the exchange of useful goods. Money, as a measure of debt, had an edge that acquired a special place in social relations. Monetary value may have induced a feeling of objectively measuring things like prestige, honor, or freedom (each related to debt), and may have acquired a psychological status independent of the material things that money could buy.

Thus money illusion can, for several reasons, be an expression of a feature of the human psyche: money has an intrinsic value for us independently of its use as a medium of exchange. For traditional economists it may seem an inexplicable irrationality. But if we regard it as a matter of taste, we have no ground for urging the "abolition" of money illusion. At most we must concede that money illusion can interfere with other goals. If we care for the welfare of people having money illusion, we have to devise policies that minimize this conflict. Therefore, there may be a social dividend to provide stability to the purchasing power of money, ensuring inter-temporal and inter-subjective comparability. Money and money illusion are intertwined, and the elimination of money illusion can occur only via the elimination of money itself: a rather unlikely event in the foreseeable future.

\section{SUMMARY AND LESSONS}

Traditional economics assumes that, by magic, people behave as if they are able to calculate real income. Money illusion phenomena show that they do not. Still, it is not necessarily a big problem for them, as I have shown in Section 4. Even if people have (necessarily) shallow knowledge, together they can prove to be smarter than individually (Sloman - Fernbach 2017). Indeed, many people's vague sense of a "real" value of money may support social institutions that defend us from making gross mistakes (indexation, artificial units of accounts, etc.). And using crisp and inter-subjective nominal representations may be a catalyst to act concertedly. Alternatively, it would be pretentious to think that money illusion can safely be ignored. Anyway, this phenomenon offers an occasion to study the role of knowledge representation on economic decisions, a topic of great interest in itself.

There are two main building blocks of the framework I apply in this paper: the non-existence of stable preferences and a theory of cognition based on that em- 
bodied in cognitive architectures. By reinterpreting the evidence I conclude that people have durable explicit nominal and implicit real representations. People may have explicit real representations, but these are fleeting. Nominal representations recur and are communicable, which makes them convenient in social interactions. Decisions are based on some nominal representations as a default, but implicit real representations may cause equivocation, and can usher in surrogate responses when people detect that nominal representations are not satisfactory.

A large part of economics is dressed in mathematical formulas, and many of these formulas refer to individual decisions by humans. By necessity economic theories entail a view on what and how human beings know about the world. Its implicit framework of declarative knowledge is that of the state-space representation: there exist objectively distinct possible states of the world, and people can observe certain events (subsets of elementary states). Rational agents are those whose views never collide with reality, but more modern theories can incorporate boundedly rational agents as well, who may be (objectively) wrong. Anyhow, the declarative knowledge base is purely symbolic. As far as procedural knowledge is concerned, rationalist theories usually postulate unlimited abilities to apply standard logic and mathematics, including the theory of probability. Again, modern approaches may weaken this assumption and may allow for mistakes in deriving conclusions relevant to actions.

Cognitive architectures are different from that picture along several dimensions. Firstly, in a cognitive architecture knowing the Kolmogorov Axioms of Probability Theory does not mean that someone can derive or use the Law of Large Numbers. Part of our knowledge resides in how and when to use procedures ("production rules"). Secondly, not all inference is deductive, procedures can be based on induction, and they can be learnt and forgotten. Thirdly, declarative knowledge may not be symbolic. Implicit knowledge is different in kind from explicit knowledge in the sense that the clear separation of the world into distinct events does not apply, and reaching "conclusions" cannot be subsumed by traditional predicate calculus or one of its extensions.

Cognitive architectures have been used to study economic decision problems, but not very extensively. It is no wonder why. To build a mathematical theory that obtains interesting conclusions is much easier with the knowledge representation so far employed by economists. In this paper I wished to point out that the issue of money illusion for the current economic modelling approaches is "beyond the pale”. In other words, every attempt to mathematically model money illusion with the state-space approach would yield spurious results, and that would, at best, deliver only trivialities about the phenomenon. I do not believe that economic thinking must be stopped when we face such a barrier. Indeed, I think that it is wrong to assume that all of economics is, or must be, model-based. It follows 
from the reasoning above: not all of our knowledge is explicit, and even if it is, it is not necessarily deductive. Therefore, I list some positive implications of the distinction between implicit and explicit representations of value for economics.

One corollary of money illusion for macroeconomists has been that the Phillips-curve (understood in modern macroeconomics as any nominal price and wage setting equation) must recognize it (Akerlof et al. 2000). My analysis suggests that the demand part of the standard macroeconomic model is also prone to correction. Variables like real balances, real exchange rates and real interest rates can be replaced with their components, i.e. nominal balances and nominal prices. For econometric investigations the implication is that it is a must to test whether "real" variables can be used in an estimation exercise at all. The current practice does not consider this testing as necessary, rather researchers check the robustness of their results by trying out different measures of real wages, real exchange rates, etc. I propose an explicit "data mining” approach, since the implicit representation of real values can be likened to data mining by the mind.

Also, a case can be developed for approaching price index theory from a psychological point of view. It is not at all obvious that all prices are represented in the same way in our minds. Some may be more important for our perception of the real value of money than others. Index number theorists have been concerned with the right measure of the cost of living, for instance, and suggested solutions to adjust for quality changes (Griliches 1961). Is it true that our mind considers new computers cheaper only because they provide better performance for the same amount of money? Or rather our concept of "computer" automatically updates it for technological advance, and for us today's average computer is exactly the same as that of five years ago?

The modern theory of monetary policy has addressed the problem of whether central banks should target low inflation or stable price levels. Though it is conceded that a stable price level has certain advantages, the consensus view is that low (zero) inflation is the correct target. However, there has been abroad a dissident view that because of money illusion and fairness considerations the correct inflation target must be somewhat higher than $1-2 \%$, so $3-4 \%$ annual inflation can be optimal (Ball 2013). This argument is based on a sort of double distortion: fairness preferences prevent necessary real wage adjustment during low inflation, but money illusion enables us to overcome this when inflation is somewhat higher. Small nominal wage increases are well received by workers, who do not realize that their real wage decreases. However, if it is true that durable explicit real representations do not exist, then all sorts of long-term decisions must suffer from money illusion in times of inflation. It follows that price level instability may play havoc with fairness heuristics. If we also believe that fairness heuristics may encourage cooperation (Heinrich 2004), then we have a reason to favour 
stable prices, not just very low inflation. ${ }^{5}$ The (social) psychological evidence (Section 5) militates in favour of the same conclusion.

I would like to add a last word concerning the future of economic theorizing. Decisions are based on several kinds of knowledge representations. To study theoretically the interactions of individual decisions - the par excellence problem of economics - one needs a framework that accommodates realistic knowledge representation with fine-grained interaction of possibly many agents. The decision-theoretical basis of such a framework must be a cognitive architecture. The type of agent-based social simulation that Sun (2006) promotes seems to be the future of a substantial segment of economic theorizing. Alternatively, a cognitive architecture must observe psychological realities, such as the possible drug-like function of money and also its social significance as a measure of debt.

\section{REFERENCES}

Akerlof, G. A. - Dickens, W. T. - Perry, G. L. (1996): The Macroeconomics of Low Inflation. Brookings Papers on Economic Activity, (1): 1-59.

Akerlof, G. A. - Shiller, R. (2009): Animal Spirits. Princeton University Press.

Anderson, J. R. (2007): How can the Human Mind Occur in the Physical Universe? New York: Oxford University Press.

Ball, L. M. (2013): The Case for Four Percent Inflation. Central Bank Review, 13(2): 17.

Berg, N. - Gigerenzer, G. (2010): As-If Behavioral Economics: Neoclassical Economics in Disguise? History of Economic Ideas, 18: 133-165.

Bewley, T. F. (1998): Why Not Cut Pay? European Economic Review, 42(3-5): 459-490.

Camerer, C. F. - Lowenstein, G. (2004): Behavioral Economics: Past, Present, Future. In: Camerer, C. F. - Lowenstein, G. - Rabin, M. (eds): Advances in Behavioral Economics. Princeton - Oxford: Princeton University Press, pp. 1-23.

Clower, R. (1967): A Reconsideration of the Microfoundations of Monetary Theory. Economic Inquiry, 6(1): 1-8.

Fehr, E. - Tyran, J. R. (2001): Does Money Illusion Matter? American Economic Review, 91(5): 1239-1262.

Fisher, I. (1928): The Money Illusion. New York: Adelphi.

Gigerenzer, G. - Hertwig, R. - Hoffrage, U. - Sedlmeier, P. (2008): Cognitive Illusions Reconsidered. Handbook of Experimental Economics Results, 1, pp. 1018-1034.

Gigerenzer, G. - Gaissmaier, W. (2011): Heuristic Decision Making. Annual Review of Psychology, 62: 451-482.

Gigerenzer, G. - Selten, R. (eds) (2001): Bounded Rationality: The Adaptive Toolbox. MIT Press.

Goldstein, D. G. - Gigerenzer, G. (2002): Models of Ecological Rationality: The Recognition Heuristic. Psychological Review, 109(1): 75-90.

Graeber, D. (2011): Debt: The First 5,000 Years. New York: Melville House.

Griliches, Z. (1961): Hedonic Price Indexes for Automobiles: An Econometric of Quality Change. In: The Price Statistics of the Federal Goverment. NBER, pp. 173-196.

5 This is only one argument, of course, that seems to contradict the accepted wisdom. 
Heinrich, J. P. (ed.) (2004): Foundations of Human Sociality: Economic Experiments and Ethnographic Evidence from Fifteen Small-Scale Societies. Oxford University Press on Demand.

Kahneman, D. - Tversky, A. (1979): Prospect Theory: An Analysis of Decisions under Risk. Econometrica, 47(2): 263-291.

Keynes, J. M. (2016): General Theory of Employment, Interest and Money. Atlantic Publishers \& Distributors.

Lea, S. - Webley, P. (2006): Money as Tool, Money as Drug: The Biological Psychology of a Strong Incentive. Behavioral and Brain Sciences, 29(2): 161-176.

Mankiw, N. G. (2009): Essentials of Economics. $5^{\text {th }}$ Edition, Cengage Learning.

Martin, F. (2013): Money: The Unauthorised Biography. London: The Bodley Head Ltd.

Modigliani, F. - Cohn, R. (1979): Inflation, Rational Valuation, and the Market. Financial Analysts Journal, 35(3): 24-44.

Pachur, T. - Rieskamp, J. - Hertwig, R. (2004): The Social Circle Heuristic: Fast and Frugal Decisions Based on Small Samples. Proceedings of the Cognitive Science Society, 26: 1077-1082.

Pigou, A. C. (1949): The Veil of Money. Macmillan.

Shafir, E. - Diamond, P. -Tversky, A. (1997): Money Illusion. Quarterly Journal of Economics, 112(2): 341-374.

Shiller, R. J. (1997): Public Resistance to Indexation: A Puzzle. Brookings Papers on Economic Activity, No. 1: 159-211.

Shiller, R. J. (1998): Indexed Units of Account: Theory and Assessment of Historical Experience. Working Paper, No. 6356, National Bureau of Economic Research.

Sloman, S. - Fernbach, P. (2017): The Knowledge Illusion: Why We Never Think Alone. Penguin.

Sun, R. (2003): Cognition and Multi-Agent Interaction: From Cognitive Modeling to Social Simulation. Cambridge University Press.

Sun, R. (2006): The CLARION Cognitive Architecture: Extending Cognitive Modeling to Social Simulation. In: Cognition and Multi-Agent Interaction from Cognitive Modeling to Social Simulation. Cambridge University Press, pp. 79-99.

Sun, R. (2015): Interpreting Psychological Notions: A Dual-Process Computational Theory. Journal of Applied Research in Memory and Cognition, 4(3): 191-196.

Thaler, R. H. (1997): Irving Fisher: Modern Behavioral Economist. The American Economic Review, 87(2): 439-441.

Tobin, J. (1972): Inflation and Unemployment. American Economic Review, 62(1): 1-18.

Weber, E. J. (1996): “Imaginary” or "Real” Moneys of Account in Medieval Europe? An Econometric Analysis of the Basle Pound, 1365-1429. Explorations in Economic History, 33(4): 479-495.

Weber, B. - Rangel, A. - Wibral, M. - Falk, A. (2009): The Medial Prefrontal Cortex Exhibits Money Illusion. Proceedings of the National Academy of Science, 106(13): 5025-5028.

Open Access. This is an open-access article distributed under the terms of the Creative Commons Attribution 4.0 International License (https://creativecommons.org/licenses/ by/4.0), which permits unrestricted use, distribution, and reproduction in any medium, provided the original author and source are credited, a link to the CC License is provided, and changes - if any - are indicated. (SID_1) 